\title{
Relationship between Serum Transforming Growth Factor $\beta 1$ Concentrations and the Duration of Type 1 Diabetes Mellitus in Children and Adolescents
}

\author{
Katarzyna Zorena, ${ }^{1}$ Dorota Raczyńska, ${ }^{2,3}$ Piotr Wiśniewski, ${ }^{4}$ Ewa Malinowska, \\ Małgorzata Myśliwiec, ${ }^{6}$ Krystyna Raczyńska, ${ }^{3}$ and Dominik Rachon ${ }^{1}$ \\ ${ }^{1}$ Department of Clinical and Experimental Endocrinology, Institute of Maritime and Tropical Medicine, Medical University of Gdańsk, \\ 81-519 Gdynia, Poland \\ ${ }^{2}$ Department of Anesthesiology and Intensive Care Medicine, Medical University of Gdańsk, Poland \\ ${ }^{3}$ Department and Clinic of Ophthalmology, Medical University of Gdańsk, Poland \\ ${ }^{4}$ Department of Endocrinology and Internal Medicine, Medical University of Gdańsk, Poland \\ ${ }^{5}$ Department of Immunology, Medical University of Gdańsk, Poland \\ ${ }^{6}$ Department and Clinic of Paediatrics, Diabetology and Endocrinology, Medical University of Gdańsk, Poland
}

Correspondence should be addressed to Katarzyna Zorena; kzorena@gumed.edu.pl

Received 24 July 2013; Accepted 2 September 2013

Academic Editor: Antonela Gverović Antunica

Copyright (c) 2013 Katarzyna Zorena et al. This is an open access article distributed under the Creative Commons Attribution License, which permits unrestricted use, distribution, and reproduction in any medium, provided the original work is properly cited.

\begin{abstract}
The aim of this study was to evaluate the relationship between serum transforming growth factor $\beta 1$ (TGF- $\beta 1$ ) concentrations and the duration of type 1 diabetes mellitus (T1DM) in children and adolescents. One hundred and sixteen patients with T1DM and 19 healthy controls were examined. Serum TGF- $\beta 1$ concentrations were measured using the cytometric bead array (CBA). A positive association between the time of diabetes duration and higher serum TGF- $\beta 1$ concentrations was observed. Similarly, the prevalence of microvascular complications, such as retinopathy and nephropathy, increased with the duration of diabetes. Logistic regression analysis showed that serum TGF- $\beta 1$ concentrations and the duration of the disease are independent risk factors of microangiopathy development. Higher serum TGF- $\beta 1$ concentrations were associated with a significant risk of microangiopathy development after 10 years of T1DM duration. In the successive years of the disease, the effect was even stronger. The results of our study indicate that serum TGF- $\beta 1$ concentrations are one of the factors that may have an impact on the progression of vascular complications in children and adolescents with T1DM.
\end{abstract}

\section{Introduction}

Along with the increase in the prevalence of type 1 diabetes mellitus (T1DM) the number of patients with chronic vascular complications will rise significantly [1-3]. One of the most specific chronic diabetic complications is diabetic microangiopathy [3-6]. Clinically, microangiopathy manifests as retinopathy, nephropathy, and diabetic neuropathysomatic as well as autonomic [4-6]. Many trials have also shown that the main determinants of the vessel damage in the course of diabetes are hyperglycemia and diabetes duration [7-9]. Diabetic microangiopathy means worsening of the quality of life and causing disability in patients with T1DM $[10,11]$. It is particularly harmful when it concerns the youngest population, which often becomes debilitated already at the beginning of the adulthood [11]. Moreover, vascular complications are also seen in children and adolescents with T1DM who suffer for more than 5 years, and the progression in this group is often more rapid than in adults $[3,12,13]$. In the Oxford Regional Prospective Study (ORPS), it has been shown that about $25 \%$ of children with T1DM develop diabetic retinopathy within 5 years of the disease duration, but already as many as $60 \%$ and $80 \%$ after 10 years and 15 years, respectively [13]. The results from 
our studies have also shown that after 5 years of diabetes duration, albuminuria was detected in $29 \%$ and nonproliferative retinopathy in $27 \%$ of children and adolescents with T1DM $[12,14]$. In the same study we have demonstrated that apart from the duration of diabetes, main factors influencing the development and progression of chronic vascular complications in children and adolescents with T1DM are growth factors, including vascular endothelial growth factor (VEGF) and angiogenin [12]. However, TGF- $\beta 1$ has not yet been studied in this context. TGF- $\beta 1$ belongs to a group of factors responsible for growth, differentiation and migration of cells, creation and degradation of the extracellular matrix, and apoptosis $[15,16]$. In addition, it stimulates the formation of blood vessels and participates in wound healing and repair by increasing the production of extracellular matrix proteins [17]. However, its adverse activity has been shown in breast cancer, myocardial infarction, rheumatoid arthritis, osteoporosis, diabetic nephropathy, and retinopathy [17-19]. This cytokine is present in five different isoforms, three of which, that is, TGF- $\beta 1$, TGF- $\beta 2$, and TGF- $\beta 3$, are coded by different genes. Out of these the best known is TGF$\beta 1$, produced by dendritic cells, leukocytes, and NK cells [15]. Despite extensive research on biology, genetics, and function of TGF- $\beta 1$, there are few reports on this cytokine in children and adolescents with T1DM. Therefore, we have assumed that it would be worth evaluating serum levels of TGF- $\beta 1$ in different groups of children and adolescents, depending on the duration of T1DM and the presence of vascular complications. Thus, the aim of our study was to evaluate the relationship between serum TGF- $\beta 1$ levels and T1DM duration in children and adolescents with T1DM with and without vascular complications.

\section{Subjects and Methods}

2.1. Studied Subjects. One hundred and sixteen patients with T1DM aged $13.3 \pm 3.9$ years with diabetes duration of $9.7 \pm 3.6$ years from the Department and Clinic of Pediatrics, Diabetology and Endocrinology, Medical University of Gdańsk, were enrolled into the study. Diabetes was diagnosed according to the Polish Diabetes Association guidelines, which correspond with the guidelines of the American Diabetes Association $[20,21]$.

The inclusion criteria for children and adolescents into the group of patients with T1DM were age less then 21 years, diabetes duration $\geq 2$ years, normal arterial pressure (systolic and diastolic), and no other chronic diseases. None of the diabetic patients were taking medications other than daily doses of insulin ( $0.83 \pm 0.21 \mathrm{IU}$ of insulin per day $/ \mathrm{kg}$ of body weight). Blood pressure was measured using a $24 \mathrm{~h}$ blood pressure monitoring (ABPM) method. Various sizes of the cuff were used according to age, weight, and arm circumference of the studied subjects. All the ABPM reports which had less than $80 \%$ of technically correct measurements were excluded from the study. Arterial hypertension was diagnosed when mean ABPM values were above the 95th centile for the corresponding age, gender, and height [22]. Ophthalmologic examination was also performed. This included visual acuity tests, intraocular pressure and anterior segment estimation using the slit lamp (Topcon SL-82, Japan). After local administration of tropicamide ( $1 \%$ solution), the eye fundus was examined using the $+90 \mathrm{D}$ lens (Ocular Instruments, USA). A digital camera (Topcon Imaginet 2000, Japan) was used for the fluorescein angiography. The stage of retinopathy was diagnosed according to the guidelines of the International Diabetic Retinopathy Division [23]. Twenty-four-hour urine collection was performed three times during the period of 6 months for the evaluation of the daily albumin excretion. The urinary albumin was measured with immunoturbidimetric assay using a Tina-quant kit (Boehringer Mannheim $\mathrm{GmbH}$, Germany). Albuminuria was diagnosed when at least two out of three urine samples displayed daily albumin excretion of between 30 and $299 \mathrm{mg} / 24 \mathrm{~h}$, collected within 6 months from patients with well-controlled diabetes with no clinical or laboratory signs of ketoacidosis. Glycated haemoglobin (HbAlc) was measured with an immunoturbidometric method using a Unimate 3 set (Hoffmann-La Roche AG, Basel, Switzerland). The normal range was $4.0-6.0 \%$.

One hundred and sixteen patients with T1DM were examined and divided into four groups based on the duration of diabetes. The control group consisted of 19 healthy children and adolescents (11 boys and 8 girls, age range 6-18 yrs). Written informed consent was obtained from all the participants in the study, or from their parents or guardians. This study was approved by the Ethics Committee of The Medical University of Gdańsk, and the investigation was carried out in accordance with the principles of the Declaration of Helsinki as revised in 1996.

2.2. Serum TGF- $\beta 1$ Measurements. The serum concentrations of TGF- $\beta 1$ were measured using the cytometric bead array (CBA) as instructed by the manufacturer's manual (Plex Flex Single Set, Becton Dickinson, USA). The samples were read in an LSR II flow cytometer using FACS Diva software (Becton Dickinson, USA). Prior to reading, the cytometer was calibrated using the calibration beads included in the test pack (Cytometer Setup Beads). Based on the FSS/SS images, the beads were gated and fluorescence was read. The analysis was performed using an FCAP Array software (Becton Dickinson, USA).

2.3. Statistical Analysis. The data were screened for obvious data entry errors, missing values, and outliers. Arithmetical means and standard deviations or 95\% CI were used to describe continuous variables, whereas proportions were used for categorical variables. A multivariate logistic regression model was fitted to the data. During the model building phase first-order interactions between the covariates were assessed. Only the interaction between serum TGF$\beta 1$ concentrations and the duration of diabetes proved to be statistically significant and was included into the final model. We assessed the marginal effects to improve the interpretation of the interaction of these two continuous covariates. The level of statistical significance was set at 0.05 . All the statistical analyses were carried out using STATA 11.0 (StataCorp, Texas, USA) statistical package. 
TABLE 1: Clinical and laboratory characteristics of patients.

\begin{tabular}{lcc}
\hline Parameter & Value & Range \\
\hline Age $(\mathrm{y})$ & $13.3 \pm 3.9$ & $4-20$ \\
Duration of T1DM (y) & $9.7 \pm 3.6$ & $3-19$ \\
Mean arterial blood pressure (mmHg) & $86.0 \pm 8.0$ & $65-105$ \\
Serum HbAlc $(\%)$ & $8.5 \pm 1.9$ & $5.8-14.3$ \\
Albumin excretion rate $(\mathrm{mg} / 24 \mathrm{~h})$ & $24 \pm 19$ & $0.20-120$ \\
\hline
\end{tabular}

Data are given as a number of subjects (\%) or mean \pm SD.

\section{Results}

3.1. Clinical Characteristics of Subjects with T1DM. A total of 116 children and adolescents with T1DM were examined. Patients with T1DM were $13.3 \pm 3.9$ years old with the duration of diabetes of $9.7 \pm 3.6$ years, mean arterial blood pressure of $86.0 \pm 8.0 \mathrm{mmHg}$, serum levels of HbAlc $8.5 \pm 1.9 \%$, and albumin excretion rate of $24 \pm 19 \mathrm{mg} / 24 \mathrm{~h}$. The clinical and biochemical characteristics of patients with T1DM are shown in Table 1.

3.2. Serum Levels of TGF- $\beta 1$ in T1DM Patients and Healthy Controls. The patients with T1DM and the presence of microangiopathy $(\mathrm{MA}+)$ displayed statistically significant higher serum levels of TGF- $\beta 1(P<0.001)$ as compared to the patients with T1DM but without microangiopathy (MA-). However, the patients with T1DM but without microangiopathy had significantly higher serum TGF- $\beta 1$ concentrations compared to the control subjects $(P<0.001)$ (Figure 1$)$.

In the patients with T1DM the relative frequency of microangiopathy was $38.8 \%$ (45 cases, $95 \%$ CI: $29.8 \%-47.8 \%$ ).

In order to study the association between the duration of T1DM and the relevant variables we divided the former into four consecutive intervals. These intervals and data related to the frequency of microangiopathy are shown in Table 2. We found 11 cases of isolated nephropathy, 8 cases of isolated retinopathy, and 26 cases where both nephro- and retinopathy were present.

We noted a significant relationship between the duration of T1DM and the concentrations of the TGF- $\beta 1$, but the HbAlc levels did not differ significantly between the subgroups of diabetes duration (Table 3, Figures 2(a) and 2(b)).

3.3. The Multivariate Logistic Regression Model. An initial multivariate logistic regression model was fitted to the data with all the relevant risk factors except for TGF- $\beta 1$. The loglikelihood value for this model was recorded. Then, serum TGF- $\beta 1$ concentrations were added to the model. First-order interactions between serum TGF- $\beta 1$ levels and the other predictors were assessed. Only the interaction between serum TGF- $\beta 1$ concentrations and the duration of diabetes proved to be statistically significant and was included into the final model (Table 4). The final model showed to fit the data significantly better compared to the initial model $\left(\chi^{2}(2)=\right.$ $11.5, P=0.003)$.

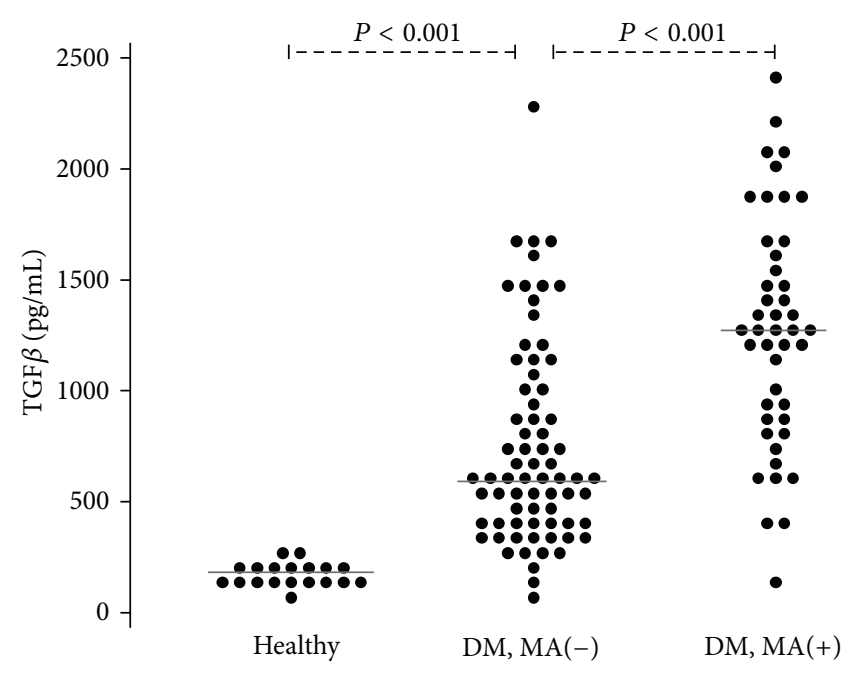

FIgURE 1: Serum concentrations of TGF- $\beta 1$ in T1DM patients and healthy controls.

TABLE 2: The number of patients with T1DM and microangiopathy depending on the disease duration.

\begin{tabular}{lcccccc}
\hline \multirow{2}{*}{ DM duration } & \multicolumn{7}{c}{ Microangiopathy } \\
& Absent & Present & $\mathrm{N}$ & $\mathrm{R}$ & $\mathrm{N}+\mathrm{R}$ & Total \\
\hline 3-6 years & 26 & 2 & 1 & 1 & 0 & 28 \\
7-10 years & 31 & 9 & 6 & 2 & 1 & 40 \\
11-14 years & 12 & 17 & 3 & 1 & 13 & 29 \\
15-19 years & 2 & 17 & 1 & 4 & 12 & 19 \\
\hline Total & 71 & 45 & 11 & 8 & 26 & 116 \\
\hline
\end{tabular}

Abbreviations: $\mathrm{N}$ : isolated nephropathy, R: isolated retinopathy, $\mathrm{N}+\mathrm{R}$ : combined nephro- and retinopathy.

TABLE 3: Means and standard deviations of HbAlc and TGF- $\beta 1$ over four consecutive DM duration intervals.

\begin{tabular}{lcc}
\hline DM duration & HbAlc $(\%)$ & TGF- $\beta 1(\mathrm{pg} / \mathrm{mL})$ \\
\hline 3-6 years & $8.5 \pm 2.4$ & $718 \pm 425$ \\
7-10 years & $8.0 \pm 1.8$ & $841 \pm 451$ \\
$11-14$ years & $8.6 \pm 1.4$ & $1069 \pm 566$ \\
$15-19$ years & $9.2 \pm 1.8$ & $1362 \pm 607$ \\
\hline
\end{tabular}

In order to estimate how TGF- $\beta 1$ influenced the occurrence of microangiopathy, given the significant interaction with the duration of DM, we analyzed the marginal effect. We noted that the increase of TGF- $\beta 1$ was associated with a significant increase of the probability of microangiopathy but after the first 10 years of DM. In the following years of T1DM duration this effect tended to be stronger (Figure 3). For example, in the 15 th year of DM, a 1 SD increase in TGF$\beta 1$ concentration was associated with a .25 (i.e., $25 \%$ ) increase in the probability of microangiopathy when remaining predictors were held constant. 


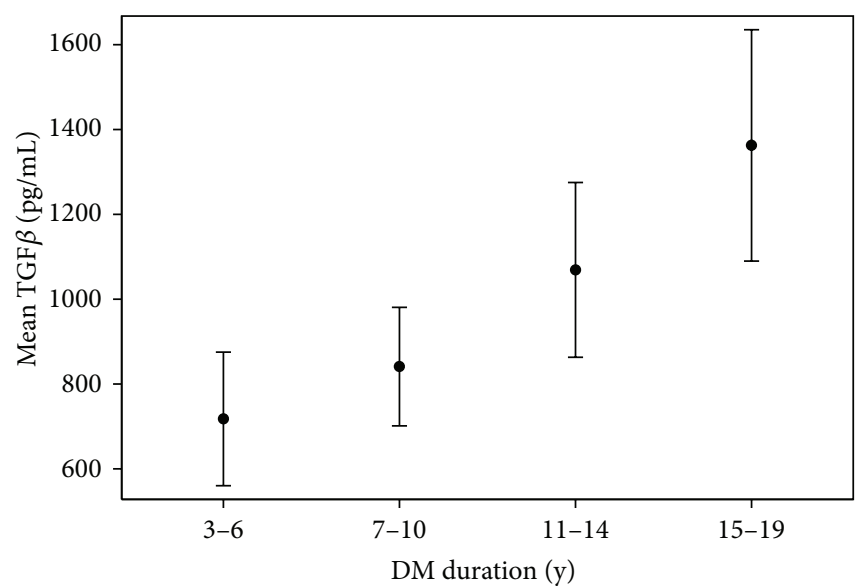

(a)

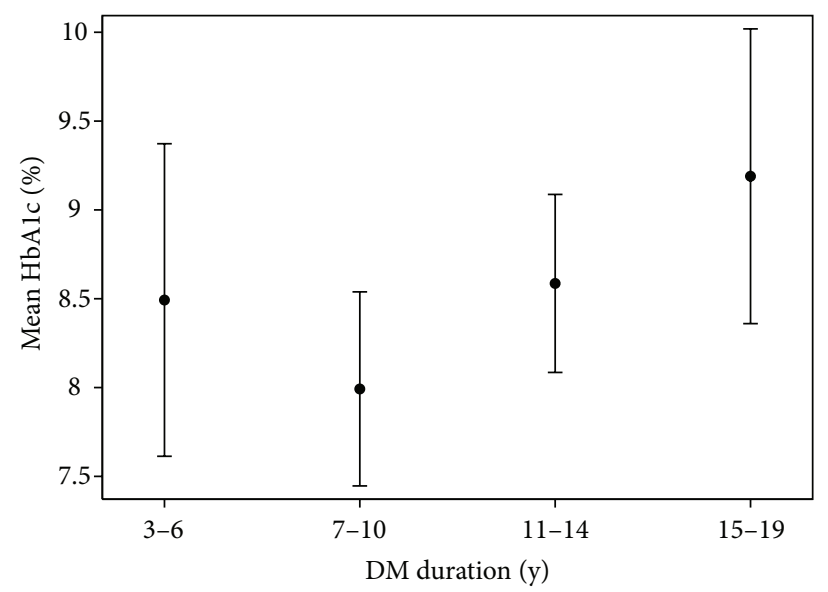

(b)

FIgURE 2: Association between duration of T1DM, TGF- $\beta 1$, and mean HbA1c Whiskers indicates 95\% CIs.

TABLE 4: The final logistic regression model for microangiopathy.

\begin{tabular}{lcccc}
\hline Predictor & $\beta$ & $-95 \% \mathrm{CI}$ & $+95 \% \mathrm{CI}$ & $P$ \\
\hline Female & 2.81 & 0.83 & 4.78 & 0.005 \\
MAP & 1.65 & 0.03 & 0.30 & 0.015 \\
Age & -0.10 & -0.34 & 0.13 & 0.396 \\
HbA1C & 0.30 & -0.16 & 0.77 & 0.199 \\
TGF- $\beta 1$ & -3.83 & -7.44 & -0.23 & 0.037 \\
DOD & 0.75 & 0.35 & 1.14 & 0.000 \\
TGF- $\beta 1 \times$ DOD & 0.49 & 0.10 & 0.88 & 0.013 \\
Intercept & -10.9 & -16.0 & -5.7 & 0.000 \\
\hline
\end{tabular}

Abbreviations: $\beta$ : unstandardized regression coefficient, MAP: mean arterial pressure, DOD: duration of T1DM, TGF- $\beta 1 \times$ DOD: interaction between TGF- $\beta 1$ and DOD.

\section{Discussion}

Previous studies have shown that the development of vascular changes in the eyes and kidneys of patients with T1DM result from many interrelated factors. Apart from well-known biochemical and hemodynamic factors, particular attention has been drawn in T1DM patients to the involvement of inflammatory factors through the production of cytokines, chemokines, and growth factors [4, 7, 24-27]. Despite the engagement of many research centers, the mechanisms leading to the development of diabetic microangiopathy in children and adolescents with T1DM still have not been fully elucidated. That is why further research is needed to solve the pending problem of chronic vascular complications in T1DM patients.

In the present study we have tried to evaluate the relationship between serum TGF- $\beta 1$ levels and the duration of T1DM in children and adolescents. We have found significantly higher serum TGF- $\beta 1$ concentrations in children and adolescents with T1DM and microangiopathy as compared with patients with T1DM but no signs and symptoms of diabetic microangiopathy. However, we have found significantly higher serum TGF- $\beta 1$ in a group of patients with T1DM

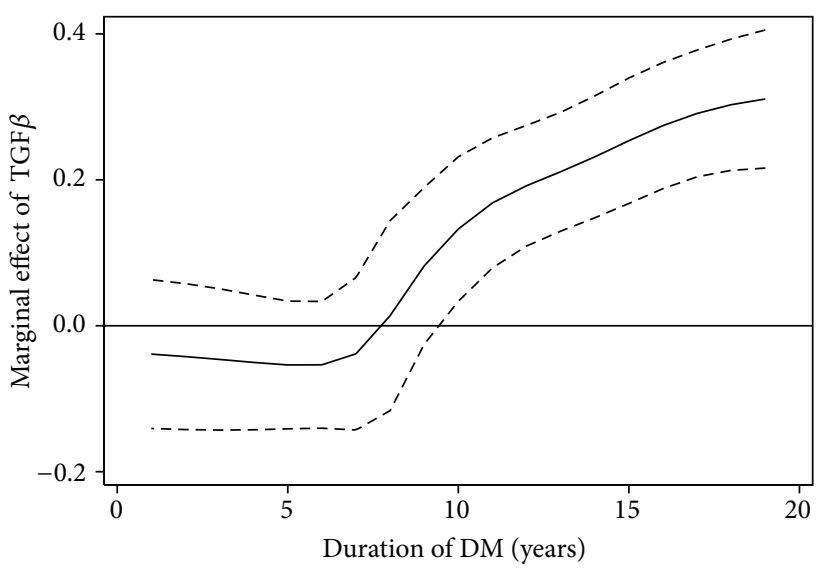

FIGURE 3: The effect of TGF- $\beta 1$ on probability of microangiopathy depending on the duration of T1DM. The dashed lines indicate the 95\% confidence interval for the effect.

but without microangiopathy as compared with the healthy control subjects. Already at this stage of the study it was found that there is an increase of serum TGF- $\beta 1$ concentrations depending on the severity of microvascular complications in children and adolescents with T1DM. In addition, we detected that the longer the duration of diabetes, the higher the concentration of TGF- $\beta 1$ in children and adolescents with T1DM. Similarly, the incidence of vascular complications was increasing over time. The multivariate logistic regression model and the assessment of the marginal effect allowed to establish a relationship between various factors and the probability of microangiopathy. The interaction between serum TGF- $\beta 1$ concentrations and the duration of diabetes proved to be statistically significant and was included into the final model. We have shown that the increase of TGF$\beta 1$ concentrations was an independent factor aggravating the likelihood of microvascular complications in our study group of children and adolescents with T1DM. This effect was statistically significant in the patients with diabetes of 
at least 10 years duration. In the successive years of the disease, a further and even stronger effect of TGF- $\beta 1$ on the development and progression of diabetic microangiopathy was observed. For example, in the fifteenth year of diabetes duration, an increase in the serum TGF- $\beta 1$ concentrations by $1 \mathrm{SD}$ was associated with a $25 \%$ increase in the probability of microangiopathy when the remaining predictors were held constant. What is more, in our recent study we established the limit for TGF- $\beta 1$ concentrations on the presence of diabetic retinopathy in children and adolescents with T1DM [28]. We suggest that in patients with T1DM, TGF- $\beta 1$ levels may correlate with the degree of eye and kidney damage. Similar results were obtained in the patients with T1DM of over 10year duration [29]. A statistical correlation between diabetes duration and the severity of morphological changes in kidney biopsy has been shown. Other researchers have shown higher intravitreal TGF- $\beta 1$ concentrations in adult T1DM patients with PDR, which in turn may be associated with retinal angiogenesis and tissue fibrosis at the vitreoretinal interface [30]. In summary, the results of our study indicate that serum TGF- $\beta 1$ levels are one of the factors that may have an impact on the progression of vascular complications in children and adolescents with T1DM.

\section{Conflict of Interests}

The authors declare that they have no conflict of interests.

\section{Acknowledgment}

The study was financed by the Medical University of Gdańsk Grant (ST-56).

\section{References}

[1] C. C. Patterson, E. Gyürüs, J. Rosenbauer et al., "Trends in childhood type 1 diabetes incidence in Europe during 19892008: evidence of non-uniformity over time in rates of increase," Diabetologia, vol. 55, no. 8, pp. 2142-2147, 2012.

[2] P. Jarosz-Chobot, J. Polanska, A. Szadkowska et al., "Rapid increase in the incidence of type 1 diabetes in Polish children from 1989 to 2004, and predictions for 2010 to 2025," Diabetologia, vol. 54, no. 3, pp. 508-515, 2011.

[3] P. Romero, M. Salvat, J. Fernández, M. Baget, and I. Martinez, "Renal and retinal microangiopathy after 15 years of follow-up study in a sample of Type 1 diabetes mellitus patients," Journal of Diabetes and its Complications, vol. 21, no. 2, pp. 93-100, 2007.

[4] P. P. C. De Almeida Salgado, I. N. Silva, É. C. Vieira, and A. C. S. E. Silva, "Risk factors for early onset of diabetic nephropathy in pediatric type 1 diabetes," Journal of Pediatric Endocrinology and Metabolism, vol. 23, no. 12, pp. 1311-1320, 2010.

[5] N. Cheung, S. L. Rogers, K. C. Donaghue, A. J. Jenkins, G. Tikellis, and T. Y. Wong, "Retinal arteriolar dilation predicts retinopathy in adolescents with type 1 diabetes," Diabetes Care, vol. 31, no. 9, pp. 1842-1846, 2008.

[6] J. T. Moser, D. R. Langdon, R. S. Finkel et al., "The evaluation of peripheral neuropathy in youth with type 1 diabetes," Diabetes Research and Clinical Practice, vol. 100, no. 1, 2013.

[7] S. Roy, K. Trudeau, S. Roy, Y. Behl, S. Dhar, and A. Chronopoulos, "New insights into hyperglycemia-induced molecular changes in microvascular cells," Journal of Dental Research, vol. 89, no. 2, pp. 116-127, 2010.

[8] N. S. Elbarbary, R. H. El-Kabarity, and E. D. Desouky, "Cochleopathy in Egyptian adolescents with Type 1 diabetes mellitus," International Journal of Pediatric Otorhinolaryngology, vol. 76, no. 11, pp. 1558-1564, 2012.

[9] M. Daniels, S. N. Dubose, D. M. Maahs et al., "Factors associated with microalbuminuria in 7,549 children and adolescents with Type 1 diabetes in the T1D exchange clinic registry," Diabetes Care, vol. 2013, 2013.

[10] K. M. P. Kumar, P. Krishna, S. C. Reddy, M. Gurappa, S. R. Aravind, and C. Munichoodappa, "Incidence of type 1 diabetes mellitus and associated complications among children and young adults: results from Karnataka Diabetes Registry 19952008," Journal of the Indian Medical Association, vol. 106, no. 11, pp. 708-711, 2008.

[11] I. Griebsch, J. Coast, and J. Brown, "Quality-adjusted life-years lack quality in pediatric care: a critical review of published costutility studies in child health," Pediatrics, vol. 115, no. 5, pp. e600-e614, 2005.

[12] K. Zorena, J. Myśliwska, M. Myśliwiec et al., "Modulatory factors responsible for neoangiogenesis in young patients with long-standing diabetes mellitus type 1," Recent Patents on Endocrine Metabolic \& Immune Drug Discovery, vol. 3, no. 2, pp. 144-149, 2009.

[13] R. Amin, B. Widmer, A. T. Prevost et al., "Risk of microalbuminuria and progression to macroalbuminuria in a cohort with childhood onset type 1 diabetes: prospective observational study," BMJ, vol. 336, no. 7646, pp. 697-701, 2008.

[14] K. Raczyńska, K. Zorena, J. Myśliwska, M. Myśliwiec, D. Raczyńska-Woźniak, and A. Balcerska, "Analysis of the proangiogenic factor influencing the development of retinopathy in children with diabetes mellitus type 1," Polish Journal of Environmental Studies, vol. 17, pp. 132-136, 2008.

[15] Å. Schiött, H. O. Sjögren, and M. Lindvall, "The three isoforms of transforming growth factor- $\beta$ co-stimulate rat $\mathrm{T}$ cells and inhibit lymphocyte apoptosis," Scandinavian Journal of Immunology, vol. 48, no. 4, pp. 371-378, 1998.

[16] F. Lebrin, M. Deckers, P. Bertolino, and P. Ten Dijke, “TGF- $\beta$ receptor function in the endothelium," Cardiovascular Research, vol. 65, no. 3, pp. 599-608, 2005.

[17] A. Maheshwari, D. R. Kelly, T. Nicola et al., “TGF- $\beta 2$ suppresses macrophage cytokine production and mucosal inflammatory responses in the developing intestine," Gastroenterology, vol. 140, no. 1, pp. 242-253, 2011.

[18] E. Gonzalo-Gil, G. Criado, B. Santiago, J. Dotor, and J. L. Pablos $\mathrm{M}$, "TGF-beta signalling is increased in rheumatoid synovium but TGF-beta blockade does not modify experimental arthritis," Clinical and Experimental Immunology, vol. 2013, 2013.

[19] A. Ho, P. H. Lee, and Y. C. Hsu, "Sustained wnt/ $\beta$-catenin signaling rescues high glucose induction of transforming growth factor- $\beta 1$-mediated renal fibrosis," The American Journal of the Medical Sciences, vol. 344, no. 5, pp. 374-382, 2012.

[20] Position of the Polish Diabetes Association, "Clinical recommendations for treatment of patients with diabetes," Journal of the Diabetes Poland Supl.A3-A7, vol. 12, 2011.

[21] American Diabetes Association, "Diagnosis and classification of diabetes," Diabetes Care, vol. 33, supplement 1, pp. S62-S69, 2010.

[22] National High Blood Pressure Education Program Working Group on High Blood Pressure in Children and Adolescents, 
"The fourth report on the diagnosis, evaluation and treatment of high blood pressure in children and adolescent," Pediatrics, vol. 114, pp. 555-576, 2004.

[23] "Classification of diabetic retinopathy from fluorescein angiograms. ETDRS report number 11. Early Treatment Diabetic Retinopathy Study Research Group," Ophthalmology, vol. 98, 5, no. 11, pp. 807-8822, 1991.

[24] K. Zorena, J. Myśliwska, M. Myśliwiec et al., "Serum TNF-alpha level predicts nonproliferative diabetic retinopathy in children," Mediators of Inflammation, vol. 2007, Article ID 92196, 2007.

[25] O. Simó-Servat, C. Hernández, and R. Simó, "Usefulness of the vitreous fluid analysis in the translational research of diabetic retinopathy," Mediators of Inflammation, vol. 2012, Article ID 872978, 11 pages, 2012.

[26] A. Gverović Antunica, K. Karaman, L. Znaor, A. Sapunar, V. Buško, and V. Puzović, "IL-12 concentrations in the aqueous humor and serum of diabetic retinopathy patients," Graefe's Archive for Clinical and Experimental Ophthalmology, vol. 250, no. 6, pp. 815-821, 2012.

[27] A. M. Abu El-Asrar, M. I. Nawaz, D. Kangave, M. M. Siddiquei, and K. Geboes, "Angiogenic and vasculogenic factors in the vitreous from patients with proliferative diabetic retinopathy," Journal of Diabetes Research, vol. 2013, Article ID 539658, 9 pages, 2013.

[28] K. Zorena, E. Malinowska, D. Raczyńska, M. Myśliwiec, and K. Raczyńska, "Serum concentrations of transforming growth factor-Beta 1 in predicting the occurrence of diabetic retinopathy in juvenile patients with type 1 diabetes mellitus," Journal of Diabetes Research, vol. 2013, Article ID 614908, 6 pages, 2013.

[29] S. M. Mauer, M. W. Steffes, and E. N. Ellis, "Structuralfunctional relationships in diabetic nephropathy," Journal of Clinical Investigation, vol. 74, no. 4, pp. 1143-1155, 1984.

[30] S. Loukovaara, A. Robciuc, J. M. Holopainen et al., "Ang-2 upregulation correlates with increased levels of MMP-9, VEGF, EPO and TGF $\beta 1$ in diabetic eyes undergoing vitrectomy," Acta Ophthalmologica, vol. 91, no. 6, pp. 531-539, 2013. 


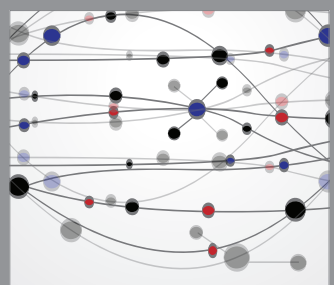

The Scientific World Journal
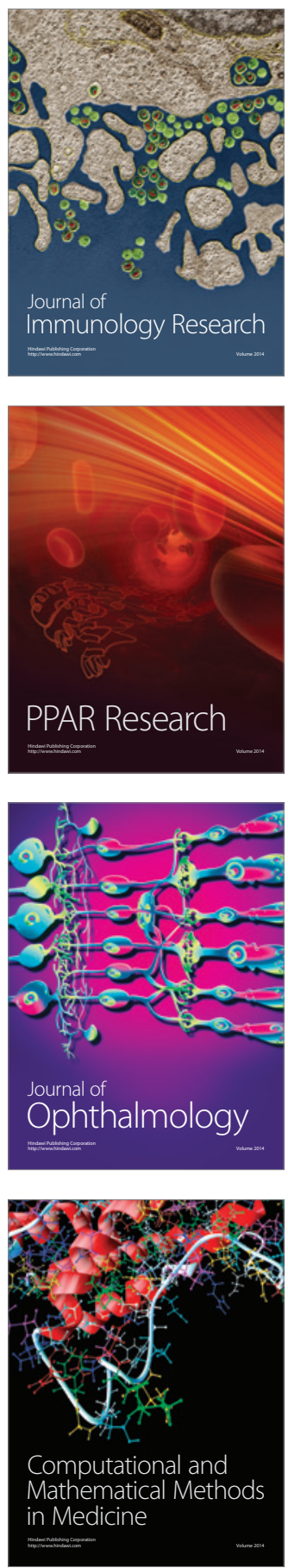

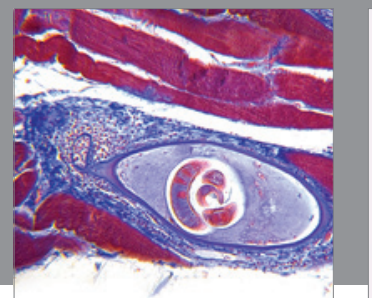

Gastroenterology

Research and Practice
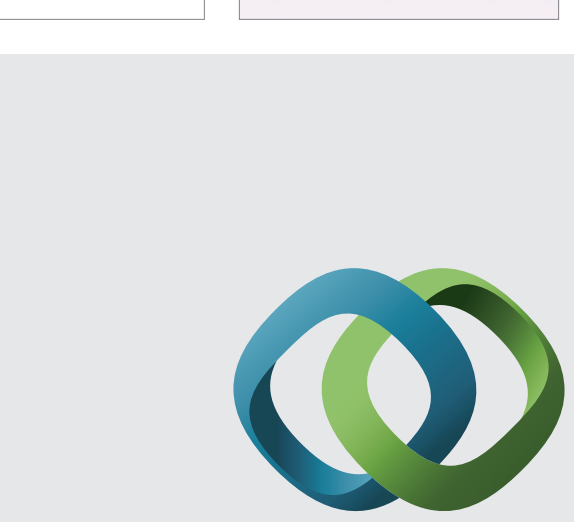

\section{Hindawi}

Submit your manuscripts at

http://www.hindawi.com
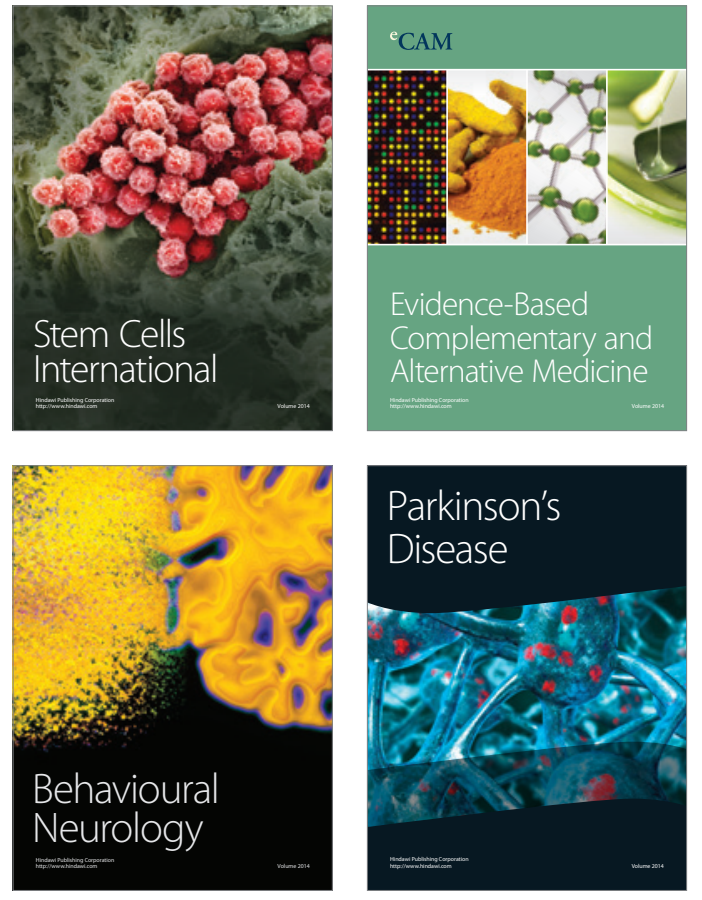
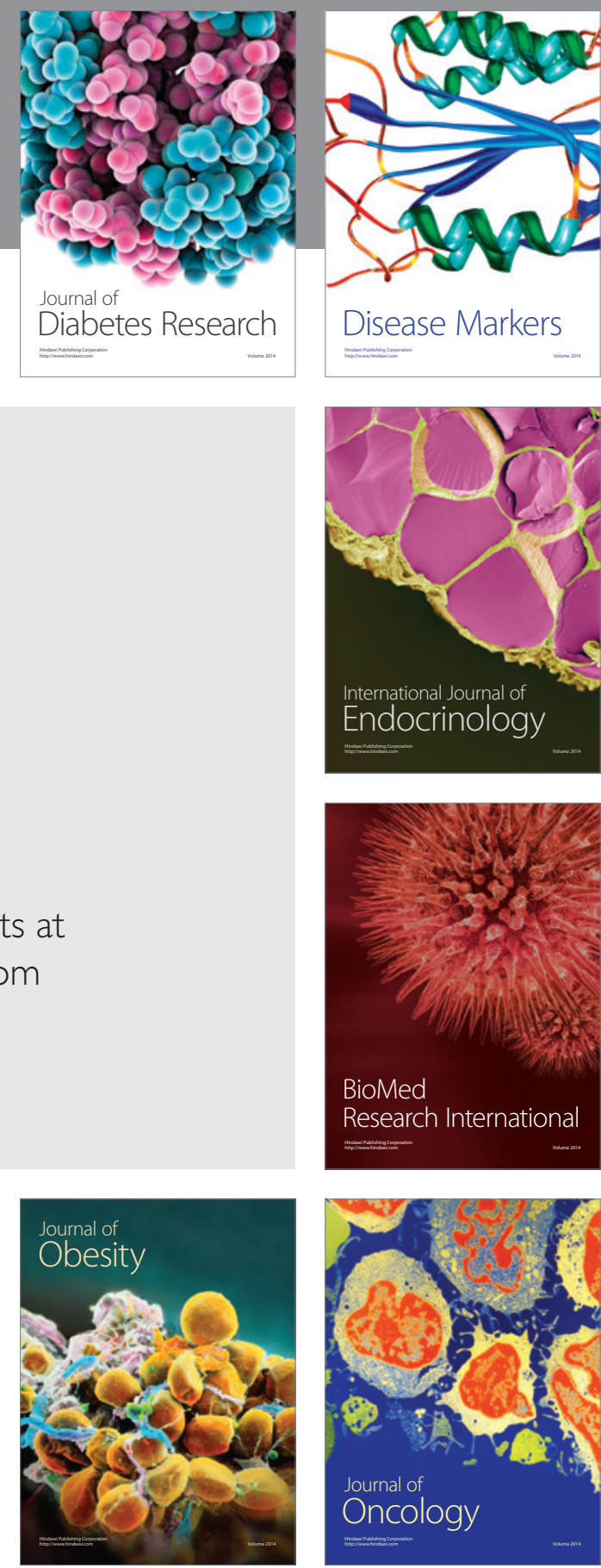

Disease Markers
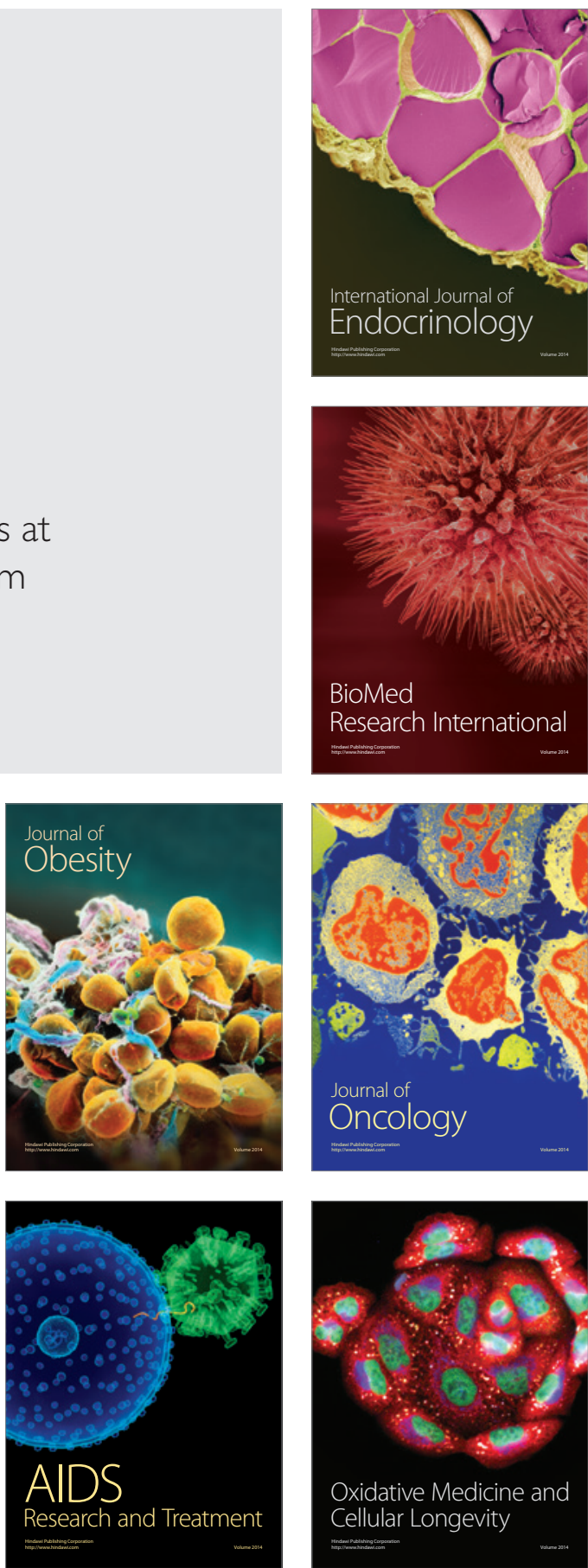